\title{
About Contemporary Problems of Numerical Modelling of Unique Structures, Buildings and Facilities
}

\author{
Alexander Belostotsky ${ }^{1,2,3}$, Taymuraz Kaytukov ${ }^{3,4, *}$, Irina Afanasyeva ${ }^{1,3}$, Jacek Grosel ${ }^{5}$ \\ ${ }^{1}$ Scientific Research Center "StaDyO"; office 810, ul. 3ya Yamskogo Polya, Moscow, 125040, Russia \\ ${ }^{2}$ Perm National Research Polytechnic University; 29 Komsomolsky prospekt, Perm, Perm Krai, \\ 614990, Russia \\ ${ }^{3}$ National Research Moscow State University of Civil Engineering, Department of Applied \\ Mathematics; 26, Yaroslavskoe Shosse, Moscow, 129337, Russia \\ ${ }^{4}$ Russian Academy of Architecture and Construction Sciences; 24-1, ul. Bolshaya Dmitrovka, \\ Moscow, 107031, Russia \\ ${ }^{5}$ Civil Engineering Faculty, Wrocław University of Technology, Wyb. Wyspiańskiego 27, 50-370 \\ Wrocław, Poland
}

\begin{abstract}
This paper is devoted to contemporary problems of numerical modeling of unique structures, buildings and facilities and corresponding directions of activity of Scientific Research Center "StaDyO" including development, verification and advanced of corresponding software, development and refinement of methods of structural analysis, solution of scientific and technical problems, scientific and educational activity. Experience in theoretical and practical computational analysis is under consideration as well (26-year history).
\end{abstract}

\section{Introduction}

International and Russian experience, reflected in the numerous papers and monographs, well-known events in the recent years in various cities all over the world indicate that problem of technological safety of metropolis is rather actual, scienceintensive and, unfortunately, still far from practical solution. An effective and economically justified solution of these problems is normally based on predictive mathematical modeling of state (static and dynamic stress-strain state, gas- and hydrodynamic state, thermal state, etc.) of structures, buildings and facilities with the use of corresponding universal and specialized software systems, realizing numerical methods of mechanics (fluid mechanics, gas dynamics, solid mechanics, structural mechanics). In accordance with the state-of-theart concept mathematical models must accompany objects at all stages of their life cycle (design and construction, operation, repair and reconstruction), providing an adequate and complete analysis and forecast of the state as part of computer-based structural health monitoring systems [1, 2]. Scientific Research Center "StaDyO" (SRC "StaDyO") was founded in Moscow in 1991 as one of the Russian pioneers offering and performing

* Corresponding author: pavel.akimov@gmail.com 
computer-oriented computation services for industrial purposes. Problems dealing with effects of static, temperature and dynamic loads on complex buildings, equipment and pipelines of nuclear and hydro power plants, wind structures, offshore structures etc. are under consideration. SRC "StaDyO" develops and distributes computer-aided design systems as well as the respective specialized software. Besides, SRC "StaDyO" distributes technical software in the area of structural mechanics and other related areas. During twenty six years SRC "StaDyO" worked in the field of design and numerical analysis of structures, equipment and pipe systems of nuclear power plants, hydro power stations and dam constructions, offshore structures and other complicated systems.

\section{Directions of Activity of Scientific Research Center "StaDyO"}

\subsection{Contemporary problems of mathematical modelling of unique structures, buildings and facilities}

Directions of activity of SRC "StaDyO" include the following contemporary problems of mathematical modelling of unique structures, buildings and facilities:

- modelling of interaction of buildings and structures with a foundation with allowance for real properties, stage-by-stage construction and actual operation history;

- structural analysis with allowance for physical, geometrical and other nonlinearities (plasticity of metal, creep and crack formation of reinforced concrete, nonlinear rheology of the foundation, large displacements, loss of stability, postbuckling behaviour, contact problems (friction separation, etc.));

- structural analysis with allowance for structural and technological specificity (structural (constructive) nonlinearity, genetic nonlinearity) of buildings and facilities (construction sequence, stage-by-stage construction, sensitivity of buildings and structures, assessment of the quality of the constructive solution from the position of the sensitivity of the stress-strain state to corresponding design deviations);

- numerical modelling of wind flows and loads (average and pulsation components, loads on facade structures, pedestrian comfort, vortex resonance oscillations), experimental validations of wind load analysis;

- seismic analysis (with allowance for acceleration spectra (versions of the linearspectral theory), accelerograms, platform models, wave effects);

- progressive collapse analysis of buildings and facilities with allowance for real dynamic highly nonlinear effects of elastoviscoplasticity and large displacements;

- development and refinement of methods and algorithms for solution of large-scale computational problems (direct and iterative solvers, superelement technology, adaptive schemes, parallelizing, etc.);

- development of calibratable mathematical and computer models as part of structural health monitoring systems at the stages of erection and operation of buildings and facilities;

- application of algorithms of aerodynamics for modelling of snow sedimentations, explosion loads and distribution of hazardous emissions;

- numerical modelling of three-dimensional non-stationary problems of fire resistance;

- solution of coupled problems of aerohydroelasticity.

\subsection{Development and verification of software}

During twenty six years specialists from SRC "StaDyO" successfully worked in the field of design, development and verification of proprietary software systems. STADYO is the universal software system providing temperature fields, static, stability and dynamic 
analysis (including response spectra and accelerations definition) as well as fracture mechanics and strength analysis and optimization of arbitrary combined 2-D and 3-D solid, shell, plate and beam mechanical systems by the finite elements, superelement and other modern numerical methods. STADYO is verified and certificated in Gosatomnadzor RF (State Nuclear Safety Commission of the Russian Federation), it is applied in the leading design and research institutes and plants (for instance, Atomenergoproject (Russia), Hydroporoject (Russia), Teploenergoproject (Russia), Energoproject (Bulgaria), Siemens AG (Germany), etc.)). ASTRA-NOVA is the software system for nuclear power plants, fuel power plants, which provides petroleum pipelines stress-strain analysis in accordance with existing Russian and international design codes. SyMonEx is informational \& diagnostic computer system of monitoring and expert safety evaluation of complicated power energetic structures. These software systems have powerful pre- and postprocessors, which allow to prepare input data and analyse results, correspond to world standards and can work together with various modern $\mathrm{CAD} / \mathrm{CAM}$ systems and data bases.

Besides, it is vital to specify the following activities:

- review of results of structural analysis with the use of verified software;

- training of specialists-users of software systems which provide mathematical modelling of structures, buildings and facilities;

- qualification tests and certification of specialists dealing with computational structural analysis and corresponding experts reports;

- verification of numerical methods and software used in design and structural analysis;

- construction and technical expertise of buildings and facilities (including cases of local destruction).

\subsection{Development and refinement of methods of structural analysis}

Research and development of numerical (finite element method, boundary element method, variation-difference method, meshless method, finite volume method etc. [3]) and semianalytical (discrete-continual) methods of structural analysis are the most important aspects of ensuring safety of structures and buildings.

Particularly the field of application of discrete-continual methods (discrete-continual finite element method, discrete-continual boundary element method, discrete-continual variation-difference method), which are now becoming available for computer realization, comprises structures with regular (in particular, constant or piecewise constant) physical and geometrical parameters in some dimension (so-called "basic" direction (dimension)). Considering problems remain continual along "basic" direction while along other directions discrete-continual methods presuppose corresponding mesh approximation. Analytical solution along basic direction is apparently preferable in all aspects for qualitative analysis of calculation data. It allows investigator to consider boundary effects when some components of solution are rapidly varying functions. Due to the abrupt decrease inside of mesh elements in many cases their rate of change can't be adequately considered by conventional numerical methods while analytics enables study. Another feature of discretecontinual methods is the absence of limitations on lengths of structures. Hence it appears that in this context discrete-continual methods are peculiarly relevant.

Solution of corresponding resultant systems of equations with immense number of unknowns is the most time-consuming stage of the computing, especially if we take into account the limitation in performance of personal computers, contemporary software and necessity to obtain correct solution in a reasonable time. However, high-accuracy solution at all points of the model is not required normally, it is necessary to find only the most accurate solution in some pre-known domains. Generally the choice of these domains is a priori data with respect to the structure being modeled. Designers usually choose domains 
with the so-called edge effect (with the risk of significant stresses that could potentially lead to the destruction of structures, etc.) and regions which are subject to specific operational requirements. It is obvious that the stress-strain state in such domains is of paramount importance. Specified factors along with the obvious needs of the designer or researcher to reduce computational costs by application of sophisticated correct discrete and discrete-continual methods cause considerable urgency of constructing of special algorithms for obtaining local solutions (in some domains known in advance) of boundary problems. Wavelet analysis provides effective and popular tool for such researches. Solution of the considering problem within multilevel wavelet analysis is represented as a composition of local and global components.

\subsection{Educational activities}

Leading specialists of SRC "StaDyO" are closely involved in development, updating and realization of Master of Science programs (in the fields of "Applied Mathematics" and "Construction") and $\mathrm{PhD}$ programs (in the fields of "Informatics and Computer Engineering" and "Engineering and technology of construction"). Besides, we should also mention here the following activities:

- "open lectures", specialized training courses, seminars, counseling (including counseling in the preparation of graduate qualification works);

- training of specialists within the programs of supplementary vocational education in the fields of large-span and high-rise buildings, underground structures, nuclear, thermal and hydroelectric power stations, pipeline systems for various purposes etc);

- organization and development of scientific research \& educational centers and laboratories in leading Russian universities;

- organization and participation in Russian and international scientific events (conferences, symposiums, seminars, etc.);

- preparation of textbooks, tutorials and monographs on topical problems of mathematical and computer simulation of the condition of buildings, structures and complexes.

\section{Experience in theoretical and practical computational analysis}

The reliability of research results, methods, algorithms, software systems and results of analysis is provided by multilevel verification and great (more than 40 -years) experience in theoretical and practical computational analysis including the following problems, specified below (Figure 1, Figure 2).

1. Three-dimensional thermal and stress-strain state, stability, strength and reliability of pipelines, technological, electrotechnical and lifting-transport equipment, machines and mechanisms, structures, coupled systems "equipment - pipelines", "foundation overground structure", "foundation - subground structure" of buildings, facilities and complexes, with allowance for design and actual load combinations (including temperature loads, static loads, wind loads, operational load (vibrations), special dynamic loads (seismic, shock-wave, emergency and other)):

- reactor compartments, engine rooms, generator halls, turbine buildings, reserve diesel power plants and cooling towers of nuclear power plants (NPP) and waste storages (Armenian, Kursk, Smolensk, Chernobyl, Leningrad, Ignalina, Bilibino, Novovoronezh, Kola, Balakovo, Volgodonsk, Kalinin, Zaporozhye, Beloyarsk, Lovisa, Kozloduy, Belene, Paksh, Temelin, Stendal, Kudankulam, Tianwan, Bushehr, new generation NPP (AS-NP 500, AS-NP 1000, NP 2006, NPP with WWER-TOI, etc.)); 


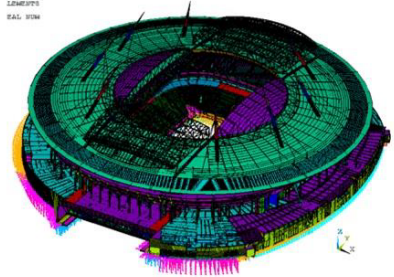

Stadium in Saint-Petersburg (540 761 nodes, 583783 elements)

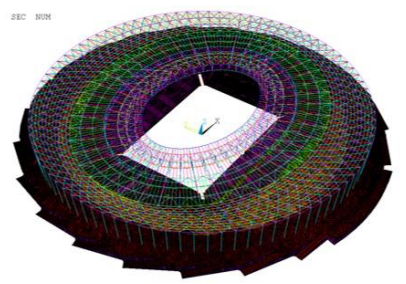

Stadium in Nizhny Novgorod (680 127 nodes, 811522 elements)

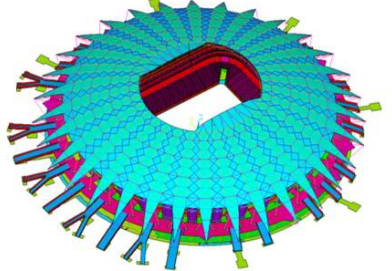

Stadium in Samara (2 013832 nodes, 2424114 elements)

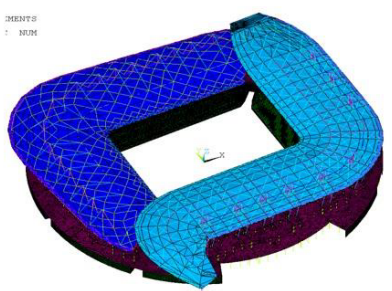

Stadium in Rostov-on-Don (480 109 nodes, 704013 elements)

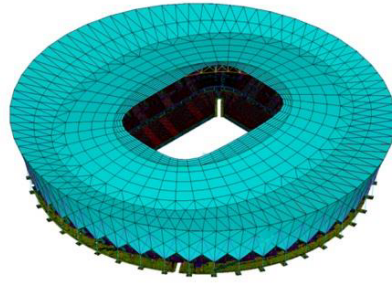

Stadium in Volgograd (540 761 nodes, 583783 elements)

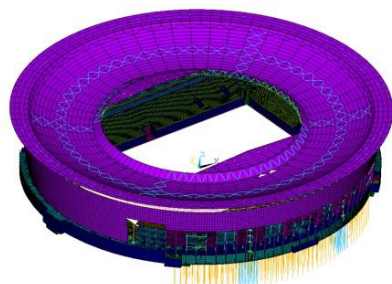

Stadium in Yekaterinburg (312 636 nodes, 350382 elements)

Fig. 1. Analysis of stress-strain state, strength and stability of load-bearing structures of football stadiums of the World Cup 2018.

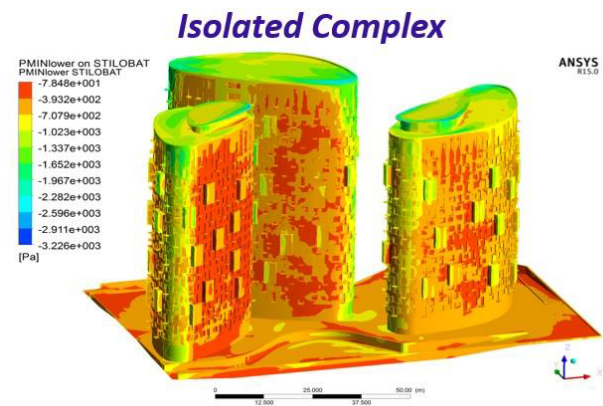

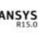

\section{Complex and existing buildings}

The envelope of the maximum values of wind pressure $(\mathrm{Pa})$ on the facade structures of the Complex.

Fig. 2. Computing of wind loads on the load-bearing and facade structures of a multi-storey complex with an apart-hotel in Moscow.

- arched, gravity and earth dams, underground structures and buildings of hydroelectric power stations (Sayano-Shushenskaya, Krasnoyarskaya, Bratskaya, Boguchanskaya, Zeyskaya, Bureyskaya, Vilyuyskaya, Katun, Chirkeiskaya, Volzhskaya, Kamskaya, Inguri, Khudoni, Namakhvani, Kurpsai, Nurek, Rogun, Plyavinskaya, Gekhi, Hoabin, Kapanda, Teri, Tang-E-Duk, etc.), hydroelectric pumped storage power stations (Zagorskaya), tidal hydroelectric stations, coast protection structures, other hydraulic strctures;

- unique and typical buildings and structures of civil engineering (roof of Grand Sports Arena of Luzhniki Olympic Complex (Moscow), the monument to the 300th anniversary of the Russian fleet (Moscow), underground parking of shopping and entertainment mall "Manezhnaya Square" (Moscow), sports and fitness complex "Aquadrom", ice stadium "Megasport" located on Khodynka (Moscow), sports complex "Moskvich" (Moscow), indoor swimming pool of the "Iskra" sanatorium (Sochi), ice palace "Bolshoi" (Sochi), bobsleigh track "Sanki" and the ski complex "Gorki" (Sochi, Winter Olympic Games 2014), football stadiums of the World Cup 2018 ("Zenit" (Saint-Petersburg), "Spartak" (Moscow), stadiums located at Volgograd, Samara, Nizhny Novgorod and Rostov-on-Don); multifunctional high-rise complexes (including Moscow International Business Center "Moscow-City", Poklonnaya (Moscow), Profsoyuznaya (Moscow), Leningradskaya 
(Moscow), building located at Volgograd, Omsk, Vladivostok, Krasnodar, Kiev, Astana), multi-block shopping and entertainment centers, multi-storey panel block sections and monolithic buildings, schools and polyclinics, banners with allowance for initial tension of ropes, wind loads and other factors);

- overground and underground pipelines of heating systems, main oil and gas pipelines, petrochemical and gas pipelines and equipment (analysis of "Sakhalin - Khabarovsk Vladivostok" gas pipeline system is among the last comprehensive and "breakthrough" researches);

- wind power plants of various types and capacities;

- floating structures and platforms for the offshore extraction of oil and gas;

- various bio- and nanostructures (for example, double linear and closed DNA (deoxyribonucleic acid) helices).

- complex mechanical engineering structures, machines and mechanisms including aerospace systems, transport, shipbuilding, power engineering, ferrous and non-ferrous metallurgy, consumer electronics, etc. (analysis of stress-strain state, dynamic response and strength of the coupled system "Science power platform - drive unit - solar batteries" and subsystems of the International Space Station (ISS) "Alpha" at the stages of launch and orbital activity.

2. Complex, including record-sized (up to 200 million unknowns) three-dimensional stationary and non-stationary problems of building aerodynamics dealing with computing of average and pulsating components of wind loads, wind loads on facade and enclosing structures, pedestrian comfort of numerous unique objects:

- high-rise buildings, structures and complexes (Moscow International Business Center "Moscow-City", "Gazoil City" (Moscow), "Zodiac" (Moscow), "Sky Fort" (Moscow), "Dirigible" (Moscow), "Rublevsky Lights" (Moscow), "Aquamarine" (Vladivostok), group of buildings of National Research Moscow State University of Civil Engineering, Ostankino TV Tower in Moscow, buildings located at Saint-Petersburg, Kiev, Astana, etc.);

- large-span buildings and structures (stadiums "Moskvich" (Moscow), "Zenit" (SaintPetersburg), railway station in Adler, a ski jumping complex of Winter Olympic Games 2014, etc.);

- monuments (monument on Poklonnaya Hill (Moscow), monuments "Conquerors of the Cosmos" and "Worker and Collective Farm Girl" at the Exhibition of Economic Achievements (VDNKh, Moscow), etc.);

- complex of basic structures of nuclear power plant with WWER (reactor compartments, engine rooms, evaporative cooling towers, etc.) with allowance for extreme (hurricane) wind and tornado.

Besides, contemporary problems of refined numerical modeling and aircraft crashes are considered for the basic structures of nuclear power plants of various types (WWER, RBMK and BN).

The Reported study was Funded by Government Program of the Russian Federation "Development of science and technology" (2013-2020) within Program of Fundamental Researches of Ministry of Construction, Housing and Utilities of the Russian Federation and Russian Academy of Architecture and Construction Sciences; Research Projects 7.1.1, 7.1.2”.

\section{References}

1. A.M. Belostosky, P.A. Akimov, Procedia Engineering, 153, 83-88 (2016).

2. A.M. Belostosky, P.A. Akimov, Procedia Engineering, 153, 89-94 (2016).

3. O.C. Zienkiewicz, R.L. Taylor, D.D. Fox, The Finite Element Method for Solid and Structural Mechanics (Butterworth-Heinemann, 2013). 